FACTA UNIVERSITATIS

Series: Mechanical Engineering Vol. 14, N ${ }^{\mathrm{o}}$ 1, 2016, pp. 113 - 120

Original scientific paper

\title{
SOLAR VACUUM TUBE INTEGRATED SEAWATER DISTILLATION - AN EXPERIMENTAL STUDY
}

\author{
UDC 621.1
}

\section{Selcuk Selimli, Ziyaddin Recebli, Semra Ulker}

Energy Systems Engineering, University of Karabuk, Turkey

\begin{abstract}
The subject of this study is the seawater distillation process enhancement through integration of the solar vacuum tube into the system. Positive effects on the rate of distillated freshwater achieved by means of the enhanced system have been investigated experimentally. Experiments were done in the Turkish city of Samsun in the Black Sea region. A distillation pond setup having the volume of $0.015 \mathrm{~m}^{3}$ and a water surface area of $0.24 \mathrm{~m}^{2}$ was constructed. The distillation pond is covered with a condensation glass and also equipped with a $0.15 \mathrm{~m}$ solar vacuum tube that is inclined at an angle of $30^{\circ}$ to the ground, a feed water tank connected with a ball cock, and distillated fresh water tank. Experimental results have shown that the rate of distilled fresh water was enhanced for about $62.5 \%$ by integrating the solar vacuum tube and the natural distillation pond. Isolation of the condensation glass not only prevents the light transmission to the pond but also heat loss from the pond; hence the rate of the distillated fresh water is increased for about $137.5 \%$ due to the natural distillation.
\end{abstract}

Key Words: Solar Distillation, Solar Vacuum Tube, Solar Pond, Seawater

\section{INTRODUCTION}

Useable water sources have been depleting rapidly by population growth, increased demands and industrial development. Most of the countries, including the United Arab Emirates, Kuwait, Libya, Japan, Qatar, Spain, Italy, Iran, suffer from the lack of fresh water sources; they try to solve this problem by seawater distillation and other alternative methods. A number of studies have been conducted with the similar aim of determining a highly efficient, economical and high rate fresh water distillation process. Suarez et al. [1] investigated solar-powered thermal desalination. They found that the heat loss reduction

Received November 15, 2015 / Accepted January 10, 2016

Corresponding author: Selcuk Selimli

Energys Systems Engineering, Karabuk University, 78050, Karabuk, Turkey

E-mail:selcukselimli@karabuk.edu.tr 
throughout the system would yield higher water fluxes, thus pointing to the need to improve the system efficiency. Gonzalez et al. [2] contributed both in the modeling issue, proposing and validating a solar field linear model, and applying an economic optimal control paradigm to solar seawater desalination plants. Gray et al. [3] discussed three alternative desalination technologies, namely, membrane distillation, forward osmosis, and capacitive deionization. $\mathrm{Li}$ et al. [4] reviewed the current solar desalination research activities, discussed the solar-assisted desalination processes and a variety of possible combinations. Aybar [5] investigated theoretically an inclined solar water distillation system. Khawaji et al. [6] considered the current status, practices, and advances of the seawater desalination technologies. Lamei et al. [7] compared the cost of seawater desalination by different solar energy technologies. Sampathkumar et al. [8] provided a detailed review of different studies on the active solar distillation system. Wu et al. [9] investigated experimentally a new multieffect solar desalination system that was based on the process of humidification/ dehumidification. Sebaii and Bialy [10] reviewed different designs of solar stills that are double, triple and multi-effect solar stills, vertical stills, tubular type solar stills, finned and corrugated stills, and stepped type solar stills. Kalogirou [11] discussed various systems that use renewable energy sources for desalination. Aybar et al. [12] studied experimentally a solar water distillation system under the actual environmental conditions. They concluded that the fresh water distillation rate increased about two to three times when wicks were used instead of a bare plate. Sampathkumar and Senthilkumar [13] studied the effective utilization of the solar water heater for solar still productivity enhancement that operates as a hybrid system. Can et al. [14] investigated technically and economically different methods to desalinate seawater in order to obtain, in this way, potable and usable water. Aydin and Ardalı [15] studied technologies for obtaining fresh water. Ketrez et al. [16] discussed the seawater distillation by solar energy. Salim et al. [17] compared three units of the solar water distillation setup which are passive solar still, passive solar still coupled with the collector, and solar still coupled with the collector supported by the copper tube to realize the latent heat. They concluded that the solar collector coupled system productivity is for about $42 \%$ higher than the passive solar still. Rajesh and Bharath [18] compared the productivity performance of the seawater distillation by a single basin still and a coupled still with the solar collector. Their study showed that the single basin still productivity enhanced for about $40 \%$ upon its coupling with the solar collector. Shabibi and Tahat [19] investigated experimentally the thermal performance of the conventional solar water still with an enhanced solar heating system. It is concluded that the fresh water yielded enhancement of about $50 \%$ by the system coupled with the solar preheater. Panchal [20] searched a double basin solar still coupled with evacuated tubes. It was found that the distillate output increased for about $56 \%$ by adding vacuum tubes and for $65 \%$ by adding vacuum tubes and black granite gravel in the double basin solar still. Rehim and Lasheen [21] presented two modifications for the solar desalination systems. They concluded that the modified solar desalination system efficiency was increased. 


\section{THEORETICAL BACKGROUND}

The energy balance of the desalination process is given by the following equation:

$$
m_{s w} c_{s w}\left(\frac{d T_{s w}}{d t}\right)=I a_{s w} A_{s w}+Q_{c(g-s w)}-Q_{c(g-e)}+Q_{u(v t)}
$$

where $m_{s w}$ is the mass of seawater, $c_{s w}$ is the specific heat of seawater, $T_{s w}$ is the temperature of seawater, $I$ is the radiative flux density, $a_{s w}$ is the absorptivity of seawater, $A_{s w}$ is the surface area, $Q_{c(g-s w)}$ is the convective heat transfer from cover glass to seawater, $Q_{c(g-e)}$ is the convective heat transfer from cover glass to environment and $Q_{u(v t)}$ is the useful heat by vacuum tube.

Convectional heat transfer between condensation glass and seawater $Q_{c(g-s w)}$ is estimated as follows [22]:

$$
Q_{c(g-s w)}=h_{(g-s w)} A_{s w} \Delta T_{(g-s w)}
$$

where $h_{(g-s w)}$ represents the convectional heat transfer coefficient [22]:

$$
h_{(g-s w)}=0.884\left(\Delta T_{(g-s w)}+\left(p_{s w}-p_{g}\right)\left(T_{s w}\right) /\left(268.9 \cdot 10^{3}-p_{s w}\right)\right)^{\frac{1}{3}}
$$

with $p$ denoting the partial pressure.

Convectional heat transfer from the condensation glass to environment $\left(Q_{c(g-s w)}\right)$ is estimated using the following equations [22]:

$$
\begin{gathered}
Q_{c(g-e)}=h_{(g-e)} A_{g} \Delta T_{(g-e)} \\
h_{(g-e)}=2.8+3 U
\end{gathered}
$$

where $h_{(g-e)}$ is the convectional heat transfer coefficient, $A_{g}$ is the condensation glass surface area and $U$ is the wind velocity.

Solar vacuum tube useful energy input to the pond is denoted as $Q_{u(v t)}$, and can be given as [23]:

$$
Q_{u(v t)}=a_{v t} I_{v t} A_{v t}-\left(E_{r r}+Q_{e}\right)-Q_{s}
$$

where $a_{v t}$ is the absorptivity of vacuum tube, $I_{v t}$ is the vacuum tube insolation, $A_{v t}$ is the vacuum tube window area, $E_{r r}$ is the reradiated energy flux, $Q_{e}$ is the convection energy to environment from vacuum tube and, $Q_{s}$ is the energy stored by vacuum tube body.

In this study, the process of obtaining freshwater by distilling seawater in a solar pond coupled with a solar vacuum tube has been investigated. Natural water circulation in the solar vacuum tube is the advantage that enables a higher rate of distilled freshwater without any external circulation energy input. The experimental study has been conducted considering the economic and environmental advantages of this process. 


\section{EXPERIMENTAL SETUP}

In this experimental study, a pond setup is constructed with $0.24 \mathrm{~m}^{2}$ water surface area, and $0.015 \mathrm{~m}^{3}$ water capacity. The constructed pond is equipped with a $0.15 \mathrm{~m}$ solar vacuum tube. Water circulation in the solar vacuum tubes occurs naturally and so it does not require any external circulation energy input into the system. The vacuum tube is inclined at an angle of $30^{\circ}$ for optimal solar light absorption. The solar pond internal surfaces are painted with black dye because of its high absorption coefficient (about 0.96). The solar pond is filled with seawater up to the level of about $0.05 \mathrm{~m}$. The feed water tank is attached to the pond with a ball cock to maintain constant water level in the pond. Firstly, the water heated by solar energy evaporates; a high temperature steam meets low temperature condensation glass and condenses. Condensed water droplets on the condensation glass come together and drip to the fresh water separation channel. Distillated water in the channel flows in a pipe line and collects in the fresh water storage tank. Water and condensation glass temperature is measured by T-type thermocouple. Potential difference between thermocouple ends is read by Voltcraft M3850 model multimeter. Solar radiation is measured by Cem DT-1307 model solarimeter. The experimental setup is illustrated in Fig. 1.

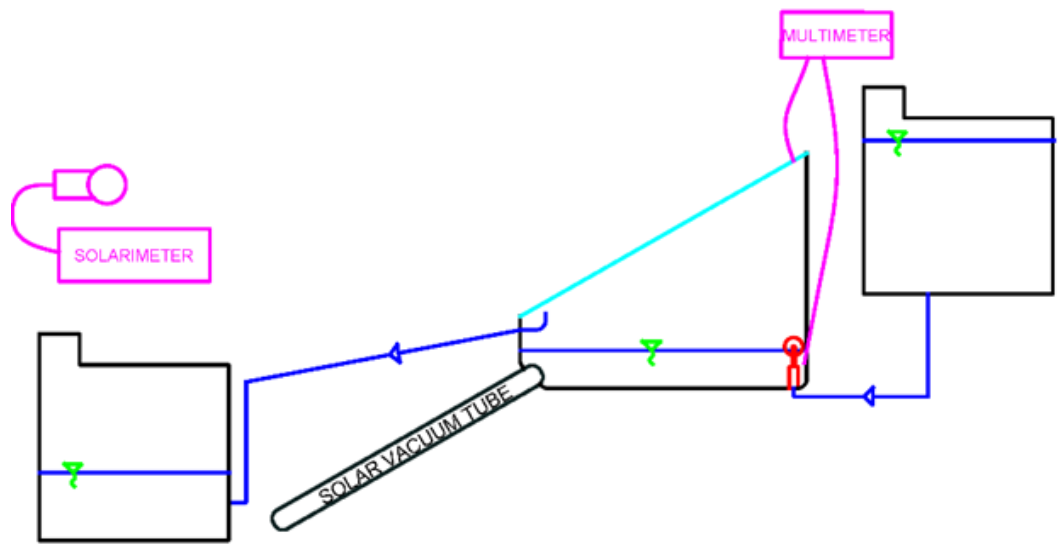

Fig. 1 Experimental setup

Distillation performance is investigated for three different setup configurations. Firstly, the solar vacuum tube is isolated and the water is exposed to solar radiation from the condensation glass. Secondly, the solar vacuum tube is uncovered and the solar penetration to the water is allowed from the tube and condensation glass. Lastly, the condensation glass is isolated and solar radiation allowed only from the solar vacuum tube. Except for the aforementioned surfaces, all other surfaces of the setup are isolated to avoid heat losses. Each configuration is studied in three consecutive cloudless spring days. Measurements were taken every 15 minutes between 10:00 am to 4:30 pm and recorded. 


\section{RESULTS AND DISCUSSION}

The obtained measurement data are evaluated and the relation between the thermal parameters and the distilled fresh water rate is assessed in this section.

Fig. 2 illustrates the temperature variation of the condensation glass for different system configurations and environmental effects with respect to the time. Solar radiative density is also given. Isolation of condensation glass prevents heat loss from the glass. Increase in the water temperature by solar energy from the vacuum tube increases the heat transfer from hot water to glass. The glass temperature fluctuates due to the variation of the flux density and heat loss from the glass surface for the non-isolated glass and vacuum tube configuration. The decrease in the temperature in the period of time between 50-100 min could be related to the low environmental temperature. The high temperature difference between the glass and the environment causes a higher heat loss from the glass than the supplied heat by solar radiation.

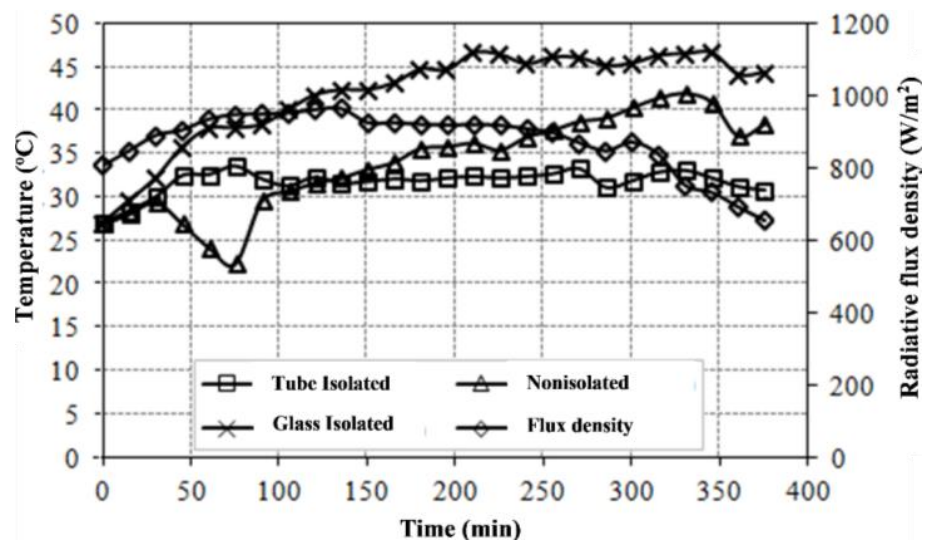

Fig. 2 Solar radiative flux density and condensation glass temperature

Fig. 3 illustrates the distillation pond water temperature and solar radiative heat flux. It shows that the transmitted natural solar radiation and the enforced radiation by the solar vacuum tube tend to increase the overall water temperature. Similar results are reported in [20] emphasizing that the integrated vacuum tube increases the water temperature compared to the single basin solar still. However, the low environmental temperature causes a higher heat loss via the glass surface than the heat supplied by solar radiation in the first hours of the experiment (between 50-100 min) and so there is a sudden water temperature decrease. The configuration with the isolated tube, i.e. with the water heating only by the natural solar radiation via the condensation glass, slightly increases the water temperature. The most efficient heating of water is provided by the isolation of the condensation glass so that the heat loss from the system is reduced thus causing a notable increase in the water temperature. 


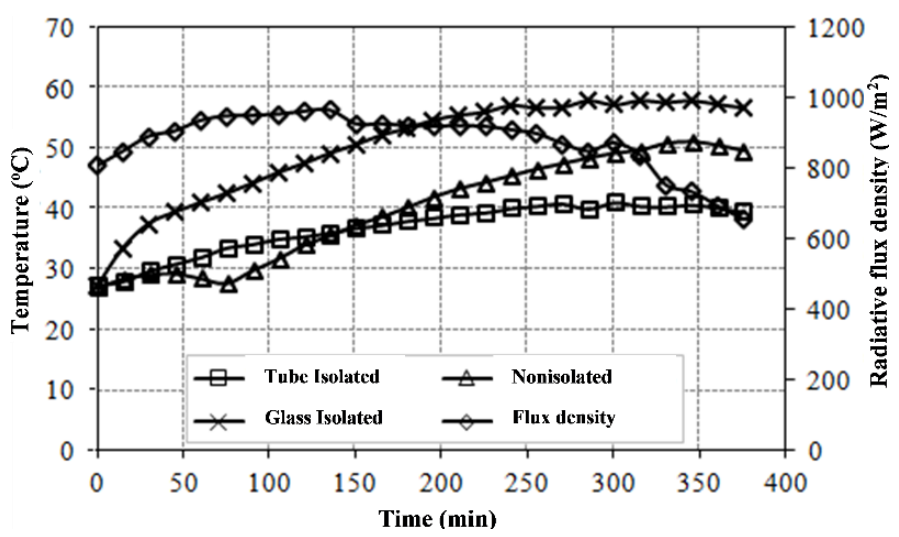

Fig. 3 Solar radiative heat flux and solar pond water temperature

Fig. 4 shows the condensed fresh water quantities obtained by the three different experimental configurations. The quantity of condensed fresh water varies depending on the water temperature, glass temperature and the heat transferred to the water. About $160 \mathrm{ml}$ of fresh water was obtained in the configuration that allowed solar radiation from the condensation glass. Low radiation heat transfer and a high heat loss via the condensation glass cause a low temperature difference (about $5^{\circ} \mathrm{C}$ ) between the water and the condensation glass. Low energy transfer means the low vaporization. Likewise, a low temperature difference leads to a low condensation rate. The non-isolated condensation glass and the vacuum tube cause a higher temperature difference and a greater heat loss via the glass surface. Also, the low temperature difference (about $8^{\circ} \mathrm{C}$ ) between the water and the condensation glass resulted in $260 \mathrm{ml}$ of distilled fresh water. The highest quantity of fresh water was obtained in the case that combined the isolated condensation glass and the non-isolated solar vacuum tube. The isolated condensation glass means a negligible amount of heat loss via the glass to the environment and the highest amount of the heat gained by the system. Additionally, the highest temperature difference (about $12^{\circ} \mathrm{C}$ ) between the condensation glass and the pond water led to the highest quantity of condensed fresh water of $380 \mathrm{ml}$.

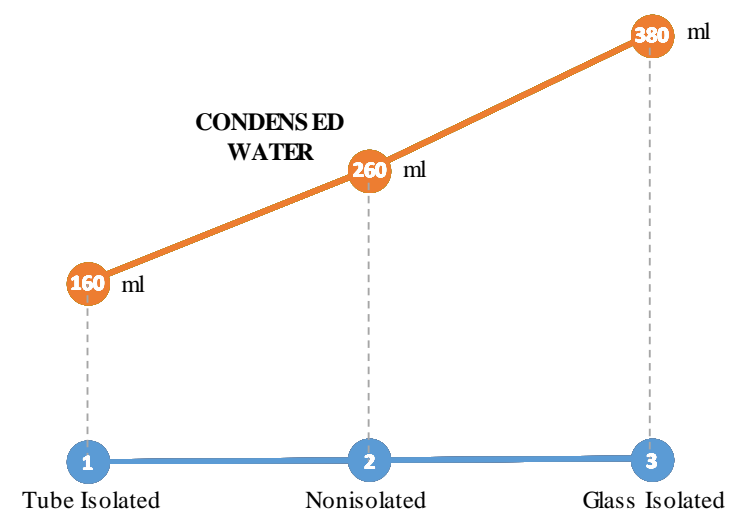

Fig. 4 Condensed fresh water quantity 


\section{CONCLUSION AND OUTLOOK}

In this study, the advantages of seawater distillation conducted on a solar pond with an integrated solar vacuum tube have been investigated experimentally. The process can be evaluated as environment friendly, economical, and efficient. The solar vacuum tube increases the gained heat energy and the quantity of distillated water. The tube has a natural fluid circulation and, hence no external circulation energy input is required. Additionally, it has a long service life and a wide range of temperature operability. The investigated distillation process is applicable to the districts that generally suffer from the lack of energy except for solar one. The fresh water distillation rate was increased by $62.5 \%$ through integration of the solar vacuum tube into the system. This result was even further enhanced up to $137.5 \%$ by the elimination of heat loss from the condensation glass. The problem of an efficient high rate of the fresh water production by alternative methods in order to solve the problem of the people living in the areas with scarce water sources has been investigated by other researchers in the field. The solar pond coupled with a vacuum tube configuration was studied in order to contribute to the studies in the field and to focus on more environment friendly, efficient, and mobile configurations which are independent of exhaustible energy.

\section{REFERENCES}

1. Suarez, F., Ruskowitz, J.A., Tyler, S.W., Childress, A.E., 2015, Renewable water: Direct contact membrane distillation coupled with solar ponds, Applied Energy, 158, pp. 532-539.

2. Gonzalez, R., Roca, L., Rodriguez, F., 2014, Economic optimal control applied to a solar seawater desalination plant, Computers and Chemical Engineering, 71, pp. 554-562.

3. Gray, S., Semiat, R., Duke, M., Rahardianto, A., Cohen, Y., 2011, Seawater use and desalination technology, Earth Systems and Environmental Sciences, 4, pp. 73-109.

4. Li, C., Yogi, G., Elias, S., 2013, Solar assisted seawater desalination: A review, Renewable and Sustainable Energy Reviews, 19, pp. 136-163.

5. Aybar, H.S., 2006, Mathematical modelling of and inclined solar water distillation system, Desalination, 190, pp. 63-70.

6. Khawaji, A.D., Kutubkhanah, I.K., Wie, J.M., 2008, Advances in seawater desalination technologies, Desalination, 221, pp. 47-69.

7. Lamei, A., Zaag, P.V., Munch, E.V., 2008, Impact of solar energy cost on water production cost of seawater desalination plants in Egypt, Energy Policy, 36, pp. 1748-1756.

8. Sampathkumar, K., Arjunan, T.V., Pitchandi, P., Senthilkumar, P., 2010, Active solar distillation - A detailed review, Renewable and Sustainable Energy Reviews, 14, pp. 1503-1526.

9. Wu, G., Zheng, H., Kang, H., Yang, Y., Cheng, P., Chang, Z., 2016, Experimental investigation of a multi-effect isothermal heat with tandem solar desalination system based on humidification - dehumidification process, Desalination, 378, pp. 100-107.

10. Sebaii, A.A.E., Bialy, E.E., 2015, Advanced designs of solar desalination systems: A review, Renewable and Sustainable Energy Reviews, 49, pp. 1198-1212.

11. Kalogirou, S.A., 2005, Seawater desalination using renewable energy sources, Progress in Energy and Combustion Science, 31, pp. 242-281.

12. Aybar, H.S., Egelioglu, F., Atikol, U., 2005, An experimental study on an inclined solar water distillation system, Desalination, 180 , pp. 285-289.

13. Sampathkumar, K., Senthilkumar, P., 2012, Utilization of solar water heater in a single basin solar still - An experimental study, Desalination, 297, pp. 8-19.

14. Can, M., Etemoglu, A.B., Avc1, A., 2002, Technical and economic analysis of desalination process, Uludag University Journal of the Faculty of Engineering and Architecture, 7(1), pp. 147-160.

15. Aydın, F., Ardalı, Y., Seawater desalination technologies, 2012, Sigma Journal of Engineering and Natural Sciences, 30, pp. 156-178. 
16. Ketrez, M., Usta, H., Cay, Y., 2012, Heat pump assisted solar energy water distillation, Journal of Sanitary Engineering, 127, pp. 5-8.

17. Salim, R.D., Al-Asadi, J.M., Hashim, A.Y., 2015, Design and manufacture three solar distillation units and measuring their productivity, Science Journal of Energy Engineering, 3(2), pp. 6-10.

18. Rajesh, A.M., Bharath, K.N., 2009, Solar still coupled with solar collector and storage tank, InterJRI Science and Technology, 1(2), pp. 62-72.

19. Shabibi, A.M.A., Tahat, M., 2015, Thermal performance of a single slope solar water still with enhanced solar heating system, Renewable Energy and Power Quality Journal, 13, pp. 1-3.

20. Panchal, H.N., 2015, Enhancement of distillate output of double basin solar still with vacuum tubes, Journal of King Saud University-Engineering Sciences, 27, pp. 170-175.

21. Rehim, Z.S.A., Lasheen, A., 2005, Improving the performance of solar desalination systems, Renewable Energy, 30, pp. 1955-1971.

22. Kumar, D., Kumar, P., 2014, Mathematical modelling of conventional solar still coupled with solar air heater, International Journal of Innovative Science, Engineering \& Technology, 1(9), pp. 379-383.

23. Winter, F.D., 1991, Solar Collectors, Energy Storage, and Materials, MIT Press, Cambridge 